\title{
Conexões
}

\section{Gênero, sexualidade e formação de professores: quo vadis?}

Vera Lúcia Pereira Brauner ${ }^{1}$

\section{RESUMO}

O objetivo desse texto é fazer uma discussão das relações entre corpo, gênero e sexualidade a partir de uma perspectiva sócio-histórica. Ao olhar para o tema proposto, e navegar pela rede mundial de computadores, foi possível nos depararmos com matérias e comentários de leitores sobre essas relações, trazendo para a cena, perspectivas dos fatos, relatos, experiências pessoais, dados de pesquisas, enfim, elementos concretos do real ou do senso comum e do ambiente acadêmico, como pano de fundo para refletirmos sobre o tema proposto.

Palavras-Chave: Corpo. Gênero. Sexualidade. Internet.

\footnotetext{
${ }^{1}$ Pontifícia Universidade Católica do Rio Grande do Sul Recebido em: 8 maio 2018

Aprovado em: 30 jun. 2018

Contato: verabrauner@yahoo.com.br
} 


\section{Gender, sexuality and teacher training: quo vadis?}

\section{Abstract}

The purpose of this text is to discuss the relationships about body, gender and sexuality from a sociohistorical perspective. By looking at the proposed theme and navigating the world wide web, it was possible to come across topics and comments from readers about these relationships, bringing to the scene, perspectives of facts, reports, personal experiences, research data, real or common sense and the academic environment, as a background to reflect on the proposed theme.

Keywords: Body. Gender. Sexuality. Internet.

\section{Género, sexualidad y formación de profesores: quo vadis?}

\section{RESUMEN}

El objetivo de este texto es hacer una discusión de las relaciones sobre el cuerpo, el género y la sexualidad desde una perspectiva socio-histórica. Al mirar el tema propuesto, y navegar por la red mundial de computadoras, fue posible encontrarnos con materias y comentarios de lectores sobre esas relaciones, trayendo a la escena, perspectivas de hechos, relatos, experiencias personales, datos de investigaciones, en fin, elementos concretos del real o del sentido común y del ambiente académico, como telón de fondo para reflexionar sobre el tema propuesto.

Palabras Clave: Cuerpo. Género. La sexualidad. Internet. 


\section{INTRODUÇÃO}

Inicialmente necessito dizer que entendo as categorias de gênero e sexualidade como próximas e articuladas entre si, e que gênero se refere aos papéis atribuídos socialmente às mulheres e aos homens e enquanto que sexualidade diz sobre a forma como vivemos nossos prazeres e desejos sexuais, sendo ambos resultados de uma construção sócio-histórica. Isto me permite afirmar que o que temos hoje, é resultado de processos que foram se constituindo ao longo do tempo. Mas, o que foi dito/escrito sobre gênero e sexualidade em outros tempos? Alguns autores arriscam algumas ideias no mínimo interessantes.

\section{Gênero E Sexualidade Da Formação EM EduCAÇÃo FísICA}

Inicio trazendo algumas ideias sobre esta construção histórico-social sobre corpo, gênero e sexualidade, a partir das representações da biologia.

Santos (2007) afirma que o conhecimento sobre a biologia humana nos ajuda a pensar a necessidade de revisitarmos o que tem sido colocado como "natural", ou da "natureza humana". Apoiado em estudos da antropóloga americana Emily Martin, Santos traz o exemplo das representações sobre reprodução humana:

O texto discute, especialmente, as ações que são atribuídas ao espermatozóides e aos óvulo, ilustrando, como a biologia, enquanto uma construção cultural, se vale de representações masculinas e femininas, para descrever a função biológica (supostamente neutra) destas células reprodutivas. [...] Enfatiza o quão femininamente o óvulo se comporta (é grande, passivo, não se move, é carregado) e o quão masculinamente o espermatozóide o faz (é hidrodinâmico, inevitavelmente ativo, tem velocidade, sua cauda é forte, tem energia, penetra, etc ...) (SANTOS, 2007, p. 88).

$\mathrm{O}$ autor segue comentando sobre a pesquisa de Emily Martin, que coloca que as representações sobre reprodução humana e os papéis dos espermatozoides e do óvulo, vêm se modificando. Além da informação de que a cauda do espermatozoide não é tão forte como se supunha, a pesquisadora aponta que são as moléculas adesivas da superfície do óvulo que capturam o espermatozoide prendendo-o rapidamente. $\mathrm{O}$ óvulo por sua vez, vem sendo descrito atualmente como uma agressora fêmea engolidora; uma viúva-negra perigosa e apavorante, ativa e determinada. Isto por si só, já dá o que pensar.

Mas sigo minhas reflexões, recorrendo a Rosa Montero, autora de Histórias de Mulheres, livro muito interessante para conhecermos histórias de diferentes mulheres, todas 
espetaculares, que mais do que nada, assumiram sua humanidade plena, com suas luzes e sombras.

Montero (2008) coloca que já nas narrativas sobre a criação do mundo aparece a mulher num papel subsidiário, mas ao mesmo tempo responsável pela perdição do mundo. É Eva quem arruína Adão por deixar-se tentar pela serpente. Na mitologia grega, é Pandora a primeira mulher criada por Zeus, a qual recebe uma caixa cheia de desgraças que ela abre liberando todos os males. Assim, Eva e Pandora, são duas mulheres apontadas como débeis, carentes de juízo. Já na tradição judaica, Eva não foi a primeira mulher de Adão, pois antes existiu Lilith. Entretanto, Lilith quis ser igual ao homem, reclamando direitos iguais (entre eles o de fazer amor em baixo de Adão). Com a negativa de Adão, ela o abandona. Segundo Montero (2008), foi a primeira feminista da criação, o que levou à fúria dos Deuses, transformando-a numa diaba matadora de crianças.

Ainda Montero (2008) nos apresenta histórias de mulheres surpreendentes e por que não extravagantes, que em diferentes momentos históricos, viveram disfarçadas de homens, mulheres guerreiras como Maria Perez, heroína castelhana que combateu vestida de homem. Resgata também Mary Read, aventureira inglesa do século XVIII e Joana d'Arc que também se vestiram de homens, colocando-se à frente de exércitos, além de Catarina, famosa imperatriz da Rússia que usava armas e tinha vários amantes como outras tantas. Por outro lado, existiam mulheres que viveram à sombra de homens como Maria Lejárraga, mulher de Gregório Martinez Sierra, famoso dramaturgo espanhol. Maria foi quem escreveu todas as obras do marido, sem nunca assina-las. Como ela, muitas outras.

No livro ela ainda destaca que outro tipo de "travestismo" ao qual as mulheres recorreram durante muitos séculos, foi o religioso: tornar-se freira. Com frequência o convento era uma obrigação, um destino compulsório, uma clausura, mas Rosa Montero diz que foi também um lugar onde era possível ser independente da tutela do homem/marido, onde podiam ler e escrever, se desenvolver intelectualmente. Fora do convento e da "vida fácil", a viuvez era a única via de libertação do domínio masculino sobre a vida da mulher.

Estes são apenas alguns casos entre os muitos existentes onde é possível perceber a condição feminina a que, durante milênios, as mulheres foram relegadas, tanto no ocidente como no oriente.

Pensando a sexualidade, o que dizer sobre a homossexualidade em meados do séc. XV, quando se constituiu pela moral judaico-cristã como o pior dos crimes, como um pecado nefando, ou seja, torpe, execrável, contrário à natureza, sendo que, no mesmo período, outros crimes hediondos eram praticados como os infanticídios, violência sexual contra crianças, matricídio, canibalismo, etc.? O que dizer da Inquisição, período no qual milhares de mulheres foram assassinadas? O livro "O Martelo das Feiticeiras", é poderoso recurso de leitura para quem estuda gênero e sexualidade, pois foi escrito por dois inquisidores e 
apresenta com detalhes as perseguições e formas de castigo às mulheres que consideravam "bruxas".

Ao olhar para a sexualidade na história como não lembrar dos gregos, que apesar de terem suas mulheres (pois a procriação era imperativa), muitos viviam suas grandes paixões com outros homens e isto não se constituía como doença, como veio a ser mais recentemente, inclusive sendo a homossexualidade incluída na lista de doenças catalogadas pela área médica como homossexualismo (o sufixo "ismo" remete à doença), termo utilizado ainda hoje por muitas pessoas.

Tânia Swain (2007) comenta que as discussões teóricas sobre homo/heterossexualidade são muito recentes, acrescentando que a "desnaturalização da heterossexualidade, apesar de já anunciada nos anos 80, só começa a tomar vulto no discurso teórico na década de 90” (p.14).

Diante deste contexto sócio-histórico são compreensíveis as interpelações dos discursos médicos, religiosos, educacionais, como poderosos dispositivos de afirmação da heteronormatividade e dos papéis atribuídos às mulheres e homens. Então pergunto sobre a homossexualidade, que sentidos habitam a violência das palavras, gestos, silêncios? Estariam ancorados nestes sentidos a exarcebação no arcabouço representacional da imagem do desvio? O desvio não suporia uma repulsa social dadas as condições de modelos determinados de ser mulher e ser homem e de uma heterossexualidade compulsória? O que determina a heteronormatividade como critério moral para a regulação da sexualidade? Será que não somos todas(os) cúmplices em relação ao silenciamento sobre a sexualidade?

Acredito que na atualidade, mais do que em qualquer momento da história do Brasil, temos o poder público atento em relação às orientações sexuais e relações de gênero. São exemplos, a Constituição Federal, a Lei de Diretrizes e Bases da Educação Nacional (Lei 9496/96), os Parâmetros Curriculares Nacionais (1996), o Programa Nacional de Direitos Humanos II (2002), o Plano Nacional de Educação em Direitos Humanos (2003), o Plano Nacional de Políticas para as Mulheres (2004) e o Programa Brasil sem Homofobia (2004). Entretanto, apesar destas ações do poder público, pesquisas apresentam dados alarmantes.

Junqueira (2007) traz informações de pesquisas como, por exemplo, estudo realizado pela Unesco em 2002, que aponta que 59,7\% das pessoas julga inadmissível que um sujeito tenha relações homossexuais. Outra pesquisa entre professores mostra que em média no Brasil, 17\% acredita ser a homossexualidade uma doença. Entre estudantes, em torno de $40 \%$ não gostariam de ter colegas homossexuais e entre pais de estudantes, 50\% não gostariam que seus filhos tivessem colegas de classe homossexuais. Ainda pesquisa realizada durante a Parada do Orgulho GLBT no Rio de Janeiro e São Paulo, em 2004, 40\% dos entrevistados declararam ter sido discriminados na escola e $32,6 \%$ identificaram a escola e a faculdade como espaço de marginalização e exclusão. 
Além destes dados, conforme coloquei no início, as ideias deste texto partiram de uma matéria encontrada no site do Terra, intitulada Estudo: comunidade escolar tem preconceito com homossexuais. Esta matéria me levou a outras duas e a seguir fui atrás do que os leitores comentavam sobre o assunto da homossexualidade e escola.

A matéria apresenta dados de uma pesquisa realizada pela USP, a qual aponta que $87 \%$ da comunidade escolar (pais, professores, alunos e funcionários), têm algum grau de preconceito contra homossexuais. Diz também - o que é interessante e nos toca especialmente - que o principal motivo para a discriminação é o despreparo dos professores para lidar com a questão. Na avaliação da coordenadora geral de Direitos Humanos do MEC, Rosiléa Wille, o professor reproduz comportamentos discriminatórios porque não foi educado para a diversidade. A matéria apresenta a história de um menino de 7 anos, que ao ser perguntado pela professora, (diante dos colegas que já haviam respondido à mesma pergunta) o que gostaria de ser quando crescesse, respondeu: quero ser mulher. A resposta chocou a escola e o menino, junto com seus irmãos tiveram que sair daquela instituição de ensino. Para ilustrar a repercussão desta matéria, fui olhar os comentários postados pelos leitores(as) e coloco aqui três deles como exemplos(a escrita é original, não fiz correções):

“É totalmente fora de propósito deixarem crianças pensarem que o sexo pode ser escolhido por nós. Se isso fosse direito nós nasceríamos sem sexo definido e a partir de uma certa idade escolheríamos nosso sexo. Senhores todos nascemos com sexo definido, até nossa anatomia é feita para haver uma relação correta entre homem e mulher. As pessoas que consideram estas posições corretas devido acharem que somos de terceiro de primeiro ou sei lá de que mundo estão confusas e perdidas. Busquem em Deus que este distúrbio pode ser curado, pois, isto é uma doença e tem que ser tratada como tal doença do espírito e da mente".

"era só o que estava faltando!! o cidadão não tem direito a ter moradia digna, hospitais públicos decentes e nem uma escola com merenda, aulas diversas e professores satisfeitos; mas tem o DEVER de respeitar o que pra mim não é normal (não defendo a homofobia, porem isso já está virando cliché)!!! “

"HOMOFOBIA SIM, PRECONCEITO SIM, QUE O VÍRUS DO HVI SE PROPAGUE EM TODOS VCS, QUE A GRIPE SUÍNA INFECTE TODOS VCS, QUE MORAM NO FOGO DO DEMO.....VCS SÃO IGUAIS AS POMBAS ......RATOS TRANSMISSORES DE DOENÇAS.”

Os comentários dos(as) leitores(as) são representações homofóbicas do público que acessa o site e que estão por aí, nas ruas, nas escolas, nas universidades. Há algum tempo, circulou também na internet um texto que tratava sobre homossexualidade e o Movimento Tradicionalista Gaúcho (MTG). A mensagem falava sobre um baile gay realizado em um salão de um Centro de Tradições Gaúchas (CTG). Dizia ser o MTG um dos maiores movimentos tradicionalistas do mundo e fazia críticas sobre o baile gay neste espaço. $\mathrm{O}$ comentário era de que os gays queriam transformar os CTG's em um mundo cor-de-rosa. 
Parecia haver um enorme temor e que o "vírus" da homossexualidade ficasse impregnado nas cadeiras, nas mesas, nas paredes de um salão de festas.

Em minha prática como professora na Universidade, venho tentando provocar minhas alunas(os) a pensarem sobre gênero e sexualidade. Uma das dinâmicas que uso é apresentar diferentes imagens colhidas na internet com bailarinos, travestis, homens e mulheres se beijando, imagens de corpos jovens e perfeitos, dentro dos padrões sociais estabelecidos com tal e de corpos velhos. Há bundas de homens, de mulheres e de velhos. A dinâmica consiste em ir mostrando as imagens e peço que as alunas(os) vão registrando em silêncio, em um papel, os primeiros sentimentos, expressões, palavras que lhes vêm à mente ao ver cada imagem. Ao final volto a passar as imagens e cada um vai comentando em voz alta seus registros. O que surge é alarmante. Expressões como nojo, loucura, doença, pouca vergonha, asco, aberração, tem que se tratar, imoral, ridículo, falta de laço, aparecem na grande maioria dos registros. Também percebo a dificuldade ou temor dos homens em verbalizar positivamente expressões sobre a imagem da bunda masculina, que era, por sinal, tão bonita quanto a feminina que coloquei e que teve elogios tanto de parte das mulheres como dos homens. A foto das nádegas de uma pessoa velha provocou também comentários, neste caso de alunos e alunas, dizendo coisas como, que horror, tá acabada, não posso nem ver isto, barbaridade, que absurdo, etc. A pergunta que fica é: quais representações de corpos têm os professores/estudantes de educação física?

Outra situação que quero colocar. Na disciplina de estágio, trabalho com textos sobre gênero e sexualidade. No semestre passado, em uma turma com 18 alunos, 17 assumiram não aceitarem a homossexualidade. A única aluna que disse aceitar, tinha um irmão gay. Todas(os) assumiram as dificuldades em pensar diferente. Colocavam sobre gênero, que a separação de meninas/meninos nas atividades esportivas em aulas de educação física, estava cristalizada nas representações existentes. Também tenho relato de alunos(as) nas diferentes instituições de ensino superior em que trabalhei, de que em disciplinas ministradas na faculdade, alguns professores separam mulheres e homens na hora da prática. Outro dado interessante é a ausência destes temas nos currículos das faculdades de Educação Física. $\mathrm{Na}$ região metropolitana de Porto Alegre, temos 8 faculdades de Educação Física. Em uma rápida pesquisa nos currículos, verifica-se que somente em uma delas há uma disciplina que pode estar tematizando corpo/gênero/sexualidade. Isto leva a pensar que, abordar o assunto, tem ficado por conta do interesse dos professores em incluí-lo (ou não) no conteúdo do semestre.

Em História da Sexualidade, Foucault afirma que condenar não avança na construção de novos saberes. Ele sugere que se possa gerir, inserir em sistemas de utilidade, administrar, e que isto deve acontecer no âmbito do poder público. Ora, como vimos antes, algumas ações públicas já vêm sendo propostas no Brasil, e se entendemos que os espaços das universidades ou das ações pedagógicas no interior da escola são espaços públicos, pergunto: quando vamos assumir a responsabilidade de problematizar gênero e sexualidade nestes lugares, onde a regra 
geral no mais das vezes é o silêncio? Silêncio que apaga, que não faz pensar, que finge que não vê, que acomoda.

Retomando as diferentes situações que apresentei, como as pesquisas da Unesco, os comentários dos leitores do site Terra sobre a matéria dos preconceitos existentes nas escolas, as preocupações sobre um baile gay em um Centro de Tradições Gaúchas, as dinâmicas que utilizo em minhas aulas, a ausência de disciplinas sobre o assunto nas faculdades de educação física, penso que é necessário que possamos nos indagar sobre como trabalhar na formação de professores de modo a sensibilizá-los que silenciar sobre estes temas, pode representar a perpetuação dos discursos e práticas sociais homofóbicas e de polarização no que diz respeito aos processos de subjetivação de mulheres e homens.

Scharagrodsky (2007) ao referir-se a estas questões diz que na escola, entre outras instituições ou lugares, é onde se fabrica a masculinidade/feminilidade. Alinhadas a estas ideias, Altmann e Souza (1999), Louro (2000), Goellner (2001) entre outras e outros, comentam sobre o processo de educação de mulheres e homens que supõe uma construção social e também corporal. Que tomar como referência padrões normativos em relação ao jeito de ser, de andar, de vestir-se, de falar, de gesticular, etc..., não avança em relação à problematização do assunto. A escola e a universidade são assim, lugares privilegiados de permanências ou de rupturas.

Como impactar, sensibilizar, fazer pensar, desacomodar ou como nos indica Louro (2004), como perturbar a familiaridade do pensamento e pensar fora da lógica segura?

Voltando ao o título deste texto: Gênero, sexualidade e formação de professores: quo vadis?, tomo o sentido de "por onde andas" ou "por onde vais", e afirmo que o tema anda ainda por caminhos onde impera o silêncio e/ou as representações hegemônicas. Acredito firmemente que em boa medida depende de cada um de nós a partir de proposições, problematizações, desconstruções em nossas práticas pedagógicas como professores e agentes sociais.

\section{CONSIDERAÇÕES FINAIS}

Penso que, a partir dos dados e fatos apresentados aqui, indagar sobre gênero, sexualidade e formação de professores se converte em um tema prioritário para nós educadores que atuamos na universidade e nas escolas, se considerarmos ser possível e/ou necessário edificar cenários onde o gerenciamento das relações de gênero e sexualidade representam nosso compromisso na elaboração de políticas e constituição de relações de igualdade e respeito às diferenças, a partir da atribuição de outros sentidos e significados a estes temas. Em fim, uma questão de direitos humanos. Scharagrodsky (2007, p. 29) complementa dizendo: 
Assim, nos diferentes lugares de formação e em especial na escola, a promoção e o respeito à diversidade, a inclusão e o pertencimento e todas as pessoas nos espaços sociais por onde circulam, deve ser encarado como paradigma social e pedagógico e efetivamente ser enfrentado como um desafio, dadas as representações ainda existentes na atualidade.

O desafio é este e depende das políticas públicas, da inclusão destes temas nos currículos de professores e especialmente do desejo de cada um de nós, educadores, pautarmos gênero e sexualidade em nossas ações pedagógicas na escola, na universidade ou nos espaços sociais por onde transitamos.

\section{REFERÊNCIAS}

ALTMANN, Helena; SOUZA, Eustáquia. Meninos e meninas: expectativas corporais e implicações na educação física escolar. Caderno CEDES, ano 19, n. 48, p. 52-68, ago. 1999.

ESTUDO: COMUNIDADE ESCOLAR TEM PRECONCEITO COM HOMOSSEXUAIS. Disponível em: < https://www.terra.com.br/noticias/educacao/estudo-comunidade-escolartem-preconceito-com-

homossexuais,00d837dabd9ea310VgnCLD200000bbcceb0aRCRD.html>. Acesso em: 24 jul. 2009.

FOUCAULT, Michel. Vigiar e punir. Petrópolis: Vozes, 1997.

GOELLNER, Silvana. A produção cultural do corpo. In: LOURO, Guacira Lopes; FELIPE, Jane; GOELLNER, Silvana (Org.) Corpo, gênero e sexualidade: um debate contemporâneo na educação. 4. ed. Petrópolis: Vozes, 2001. p. 28-40.

JUNQUEIRA, Rogério. O reconhecimento da diversidade sexual e a problematização da homofobia no contexto escolar. In: SEMINÁRIO CORPO, GÊNERO E SEXUALIDADE: DISCUTINDO PRÁTICAS EDUCATIVAS, 1., 2007, Rio Grande. Anais... Rio Grande:: FURG, 2007. p. 59-69.

LOURO, Guacira Lopes. Gênero, sexualidade e educação. Petrópolis: Vozes, 1998.

MONTERO, Rosa. História de mulheres. Rio de Janeiro: Agir, 2008.

PESQUISA: DIVERSIDADE SEXUAL NÃO CHEGOU AOS LIVROS DIDÁTICOS. Disponível em: <https://www.terra.com.br/noticias/educacao/pesquisa-diversidade-sexualnao-chegou-aos-livros-didaticos,80d837dabd9ea310VgnCLD200000bbcceb0aRCRD.html>. Acesso em: 24 jul. 2009. 
PROFESSOR DESPREPARADO POTENCIALIZA O PRECONCEITO NAS ESCOLAS. Disponível em: <http://noticias.terra.com.br/educacao/interna/0,,OI3890521-EI8266,00Professor+despreparado+potencializa+o+preconceito+nas+escolas.html>. Acesso em: 24 jul. 2009.

SANTOS, Luis. O corpo que pulsa na escola e fora dela. In: SEMINÁRIO CORPO, GÊNERO E SEXUALIDADE: DISCUTINDO PRÁTICAS EDUCATIVAS, 1., 2007, Rio Grande. Anais... Rio Grande: FURG, 2007. p. 80-92.

SCHARAGRODSKY, Pablo. Masculinidades en acción: machos, maricas, subversivos y complices. In: SEMINÁRIO CORPO, GÊNERO E SEXUALIDADE: DISCUTINDO PRÁTICAS EDUCATIVAS, 1., 2007, Rio Grande. Anais... Rio Grande: FURG, 2007. p. 1830.

SWAIN, Tânia. Lesbianismos, cartografia de uma interrogação. In: SEMINÁRIO CORPO, GÊNERO E SEXUALIDADE: DISCUTINDO PRÁTICAS EDUCATIVAS, 1., 2007, Rio Grande. Anais... Rio Grande: FURG, 2007. p. 9-17.

TRAVESTIS E TRANSEXUAIS SÃO OS MAIS PREJUDICADOS NA ESCOLA. Disponível em: <https://www.terra.com.br/noticias/educacao/travestis-e-transexuais-sao-osmais-prejudicados-na-escola,20d837dabd9ea310VgnCLD200000bbcceb0aRCRD.html>. Acesso em: 24 jul. 2009. 